\title{
A Cluster of Mistrust: Safety in the Mining Industry
}

\author{
Neil Gunningham and Darren Sinclair \\ The Australian National University, Australia
}

\begin{abstract}
This article examines the relationship between mistrust, adversarial industrial relations and safety performance in ro Australian coal mines, across three mining companies. Based on case study research and company safety data, the article identifies a 'cluster of characteristics' closely associated with the formation of mistrust, and examines the negative impact such characteristics can have on safety performance. The article considers the broader ramifications of these findings for non-mining sectors, in particular for companies with a corporate head office overseeing separate sites, and identifies ways of building trust.
\end{abstract}

Keywords: mining; mistrust; OHS; safety; trust

\section{Introduction}

There is growing evidence that trust between corporate and site management, and between management and the workforce, is crucial to improved safety outcomes. Indeed, trust is often referred to as the lubricant for open and frequent safety communication (Reason, I997), and as crucial in maintaining cooperation (Morgan and Hunt, I994), promoting the acceptance of decisions

Contact address: Darren Sinclair, Fenner School of Environment and Society, The Australian National University, Canberra ACT 0200, Australia.

[email: darren.sinclair@anu.edu.au] 
(Tyler, 2003), improving knowledge-sharing (Dirks and Ferrin, 2002), supporting all aspects of organizational functioning (Bijlsma and Koopman, 2003) and enhancing safety performance (Barling and Hutchinson, 2000). Lack of trust is closely associated with a history of adversarial industrial relations, although a number of other factors also contribute to its development.

Trust can be regarded as an individual's or group's belief that another individual or group makes good faith efforts to behave in accordance with explicit or implicit commitments, is honest in negotiations preceding such commitments, and does not take excessive advantage of the other, even when the opportunity arises (Cummings and Bromley, I996). In the context of worker and management relations around safety, trust is best understood as an individual's willingness to rely on another person, based on expectations that he or she will act safely or intends to act safely. For example, management might trust workers not to 'cut corners', break safety rules or take unreasonable risks. Workers in turn might trust management to keep them safe (Risk Analysis, 2006).

Notwithstanding the crucial importance of trust to improving safety performance, there is a paucity of research examining the concept within the realms of safety (Cox et al., 2004). There is still much we do not know about how trust is best nurtured, how it is lost and might best be regained, the consequences of an absence of trust, how it varies between different groups within an organization, and the relationship between trust and industrial relations (Conchie et al., 2006; Risk Analysis, 2006; Zeffane and Connell, 2003).

This article explores trust in the context of the Australian mining industry, an industry that has more reason than most to have major concerns about a lack of trust, given its long history of acrimonious industrial relations. Indeed, the 2005 New South Wales Mine Safety Review identified a 'debilitating mistrust between the members of the tripartite process' (Wran and McClelland, 2005) as a principal obstacle to improved safety in the industry. In Western Australia, the Ritter Report documented the enormous difficulties of successfully implementing managerial safety strategy with 'a workforce of whom a significant number had strong opposition to a key management strategy' (Ritter, 2004). In Queensland, a 2005 report pointed to a series of disputes that have had a detrimental effect on trust between the inspectorate, the Construction, Forestry, Mining and Energy Union and mine operators, and the antagonistic and confrontational climate that is not conducive to optimal safety outcomes (ACIL Tasman, 2005).

In Tasmania, the report of the investigation of the Beaconsfield Gold Mine collapse provides several pertinent insights (Melick, 2006). In particular, the report detailed that there was a prevailing atmosphere of mistrust that had undermined safety reporting and responses prior to the incident (Quinlan, 2007). Further, it highlighted the limitations of relying on 'top-down' safety management, which in turn can undermine worker perceptions of the effectiveness of, and trust in, corporate safety initiatives (a phenomenon that may be replicated across the industry). Finally, in his concluding report, the Coroner 
highlighted the failings of risk assessments that did not adequately consult workers (Chandler, 2009).

There are a variety of reasons why building trust is far from easy in the mining industry. For many years, workers and management have been polarized on a plethora of issues; relations between unions and mining companies are often acrimonious; and although safety might arguably be kept separate from industrial relations (Carson and Hennenberg, I988), in practice, it is often ensnared within it (Creighton and Gunningham, I985). Hostile labour relations, it is argued, may be further entrenched within export-oriented and/or foreign-owned companies (as applies to many Australian coalmining companies, and two of the three companies in this research), which have historically been less amicable towards Australian labour interests (Bennett, 1994).

Notwithstanding the argument that there is no place for industrial relations in safety because both sides have common interests (Robens, I 972), this is not a view supported by history. On the contrary, in the event of disagreement (as when the production process is speeded up to the detriment of safety), common interest evaporates (Berman, 1978; Carson, 1981; Nichols and Armstrong, I973). On this view, industrial relations and safety cannot be kept apart. As such, achieving a cooperative and constructive approach to safety, and enlisting worker participation to improve safety outcomes, presents an enormous challenge, which is unlikely to be resolved in the absence of trust.

In the Australian mining industry (and coal-mining in particular), trust has been an extremely scarce commodity. Many managers express a strong mistrust of union-dominated workforces and of union representatives in particular, and, even in the absence of unions, regard the entrenched attitudes and behaviours of many mine-workers as being antithetical to modern management and improved safety outcomes. In turn, many workers and their representatives have a deep mistrust of, and hostility towards, management borne from a history of death, injury and disease for which employers were, historically, hardly blameless (Hargraves, I993; Shaw and Bruns, 1947). Lockouts, strikes and the use of leverage (by both sides, depending on the economic climate) have also left their scars (McColl, I982), reinforcing negative stereotypes. The fact that both government and employer priorities sometimes seemed to exclude safety considerations, and that the 'welfare of mine workers and families is regarded as subsidiary' (Bullimore, I999), served to entrench worker mistrust.

This article examines the relationship between trust (and mistrust) and safety. The second section outlines the methodology and the third section describes a cluster of characteristics identified as being at the heart of mistrust between workers and management. The fourth section discusses the implications of these findings, including the interaction between different characteristics and a 'tipping point' beyond which mistrust becomes both entrenched and a potent constraint on safety. The article concludes with some comments on how mistrust might best be overcome and trust created. 


\section{Methodology}

This research was based on in-depth interviews with corporate and mine management, union officials and miners across ro mine sites, three companies (four each from the first and second companies, and two from the third) and two states (eight in New South Wales and two in Queensland). The intention was to identify and examine (where they existed) critical relationships between safety and trust (or a lack thereof). Researching different mine sites within individual companies enabled a number of variables to be held constant across those companies (in particular, corporate management approaches and safety systems) while exploring variation in others (namely, differences in safety performance and levels of trust at the mine site level).

We began by identifying high and low safety-performing mine sites within each of the companies (and avoiding sites in the middle of the spectrum) - no attempt was made to pre-judge individual mine sites as being either high or low in trust. To do this, internal Occupational Health and Safety [OHS] statistical measures (including lost time due to injuries, total recordable injuries, incident reporting and workers' compensation data), together with the annual results of internal company safety audits, were collated over a five-year period ${ }^{\mathrm{I}}$ and then aggregated and weighted (with the weighting factor of 5 given to the most recent year's data, stepping down by I through each year to a factor of I for the five-year-old data) to give each mine a safety-performance ranking (the combination of different statistical data makes it more reliable than if we relied on, in particular, lost time injury data alone, which has been subject to legitimate criticism of being open to manipulation; see Hopkins, 2002b). In addition, corporate managers (including corporate safety managers) provided a subjective (and independent and confidential) ranking of the safety performance of the mine sites within each of their respective companies.

The combined ranking process produced three striking results. First, there were very large differences in the aggregated statistical weightings between the highest- and lowest-ranked mines. Second, the spread of mines was highly polarized, with distinct groupings at the high, middle and low rankings. Third, there was a very high degree of consistency between the quantitative (aggregated statistics) and qualitative (managers' views) rankings, with only limited differences in the middle rankings. On the basis of these results, then, mine sites for inclusion in the research project were selected from only the highest and lowest safety rankings. This methodology was deemed sufficiently robust for the purpose of this research project (which was, simply, to identify mine sites within each company at either end of the safety-performance spectrum, and not to identify and quantify in detail the precise gradations across the entire spectrum). ${ }^{2}$

Following the selection of high and low safety-performing mine sites, fieldwork was conducted between August 2007 and May 2008 with the full cooperation of the participating companies, key unions and the workforce. The principal means of data collection was semi-structured interviews as this method yields more unexpected insights and candid revelations than a more 
structured interview or survey method, and allows the interview to be tailored to the circumstances and experiences of each interviewee.

A total of 120 interviews were conducted. In each two-day site visit, I 2 interviews were typically conducted spanning senior, middle and line management, and workers. The balance of management and worker interviews was approximately equal. In addition to the site interviews, I 2 representatives from corporate management (including chief executives, corporate safety managers and operational managers) were interviewed across the three participating companies. Twelve inspectors were interviewed across both jurisdictions, including mines inspectors and electrical and mechanical engineering inspectors, and discussions were held with a chief mines inspector. Six union officials were interviewed across both jurisdictions (either district check inspectors, industry safety representatives or industry check inspectors), and discussions were held with a senior union official. Generally, interviews lasted between 40 and 60 minutes, were conducted in private (but in the field), and consisted of a series of questions or prompts addressing the following topics: the nature of their relationship, communication and history with their superiors, subordinates and/or peers (in the case of company managers and workers, and depending upon applicability); the nature of their relationship, communication and history with company managers and workers (in the case of union officials and inspectors); the impact of these relationships on safety practices and performance; and their perceptions of company safety policies and procedures. Interviewees were provided with an information statement of the research project and a consent form (signed by each participant), and were informed in advance that all information arising from their interviews would be treated confidentially and used anonymously in any subsequent publications. ${ }^{3}$

Qualitative data arising from the interviews was subject to 'grounded theory' - this entailed transcript material being codified and collated into 'like' categories, which in turn were analysed for relationship patterns and used to inform our research findings (Charmaz, 2006). The qualitative data was supplemented by reviews of the domestic and international literature and internal policy and safety-related information provided by the three participating mining companies.

\section{Findings: A Cluster of Mistrust}

The mine sites with low safety performance displayed a cluster of characteristics strongly associated with a heightened presence of mistrust. This is not to suggest that all the lower-performing sites expressed identical characteristics, or that such characteristics were uniformly displayed throughout each site, or that mistrust is the only factor at play. Nevertheless, it became clear that not only is mistrust a central theme running through each of the characteristics included in the cluster, but that combinations of these characteristics had a tendency to interact. Overall, the greater the number of the characteristics, the greater the likelihood that mistrust impacted negatively on safety processes, practices and outcomes. 
The cluster of characteristics closely associated with the formation and maintenance of mistrust (and, conversely, their absence with high trust) were: (I) a catalytic event; (2) a divided workforce; (3) mixed messages, inconsistent actions; (4) a high turnover of senior management; (5) a closed management style; and (6) a resentment of corporate intervention. In identifying these characteristics, our primary interest was in the factors underlying mistrust, not its subsequent effects.

\section{A Catalytic Event}

In many of the lower-safety sites, a single catalytic event had precipitated a serious breakdown of trust between management and workers. For example, one mine experienced a mishandled downsizing, where all worker positions were 'spilled', and workers who wanted to resume working at the mine had to reapply, generating considerable fear and uncertainty. The consequences in terms of animosity between workers and the managers perceived to be responsible continued for several years. At two other mines, management 'cut coal' during the course of industrial disputes, crossing the picket line to do so. This meant that management was able to hold out for much longer than would otherwise have been the case, and in so doing put considerable pressure on workers to reduce their demands. This action generated acrimony that continued several years after the event.

Although the precise events varied from case to case, there were striking similarities between the mines that had experienced such an event in terms of their negative consequences. Such events created a ripple effect throughout a mine site's operations, with mistrust infusing relationships outside the original context. For example, a dispute concerning a specific incident might impede good management and worker communications more generally, with a corrosive effect on safety initiatives. The ill feeling on the part of the "wronged' party (usually workers) often persisted for years, flaring up at points of stress, such as changes in management practices or structures.

In terms of safety, a particularly debilitating consequence of a catalytic event is its potential to reshape perceptions. Subsequent disputes or disagreements become framed in such a way as to reinforce prejudices arising from the original event. In consequence, even when senior management introduces safety initiatives in a genuine attempt to raise standards, these may fail to penetrate a powerful cultural mythology of mistrust. Where this mistrust was not overcome, workers treated almost all management safety initiatives with suspicion and refused to buy into them, safety observations were perfunctory, incidentreporting was trivialized or ignored, systems were honoured more in the breach, and sophisticated electronic monitoring systems were sidetracked. This suggests that once lost, trust may be particularly hard to regain.

\section{A Divided Workforce}

A second feature found in four lower-safety mine sites was the presence of highly visible and distinctive divisions within the site workforce, such as 
between workers on staff agreements and those on collective agreements (or enterprise agreements); between miners who had been rehired in the face of an impending pit closure and those who had not; between managers (and some workers) who had come over to a new mine as a 'block' from another mine and those already employed at the recipient mine; and between company employers and contractors.

Clearly, all work environments to a greater or lesser extent are prone to the formation of cliques or factions. What was distinctive here was the ways in which such divisions became a prominent feature of the prevailing work culture. At one mine, individual contracts (as opposed to collective agreements) were offered to workers, the inducement to sign such contracts being a higher pay structure. Among miners, a commonly voiced opinion was that there was a management attempt to divide and conquer, with the strategy being to get enough of a core of workers to run the mine without the union. The fact that some union members chose to go on to contracts created a high degree of animosity, which was directed at those who accepted management's offer to go on to contracts by those who did not. Threats were made and individual contract workers were ostracized. Outside, property (such as private vehicles) was damaged, and the extended community of miners' families was split.

Such divisions generated a tension that undermined both productivity and safety. It is difficult to maintain high safety standards when one group of workers will not speak to another group.

\section{Mixed Messages, Inconsistent Actions}

A third characteristic associated with mistrust, and common at lower-safety mines, was a perception of management giving 'mixed messages' and failing to 'walk the talk' in terms of safety. The most commonly cited example of such behaviour involved management exhorting workers to 'put safety first', while placing greater pressure on them to achieve production targets (these two goals commonly being in tension).

For example, at one mine, workers were required to complete a job safety analysis (JSA) card at the start of each shift and when starting a new job. However, workers told us that management had not provided adequate training or allocated time to complete the cards. Instead, they reported that if they took the time out to complete a card, they would incur the wrath of management for wasting time. In short, there is a strong 'production comes first' message undermining the value of the programme. This in turn leads to tokenism. Miners admitted that it was common practice to take a week's worth of JSA cards home and complete them in advance of the actual jobs, completing them without thought to actual risks or safety mindfulness as a 'tick-and-flick' exercise, or completing them after the job.

Such mixed messages and management turning their backs on workers not doing things in the safe way generated cynicism and mistrust. There was a widespread view that the real purpose of safety initiatives is 'arse-covering' by management. 
One aspect of management inconsistency that is deeply resented by workers and enormously damaging to trust is when there is a perceived breach of 'noblame' policies. Many companies have introduced such policies in relation to the reporting of incidents, accidents and equipment damage, as one important step towards establishing a safety culture (Reason, I997). However, in some of the lower-safety sites the no-blame policy was not evenly applied. At one mine, for example, workers acknowledged that they were not reporting 'micro-sleep' incidents (where a worker momentarily falls asleep on the job), notwithstanding the fact that such incidents could be extremely dangerous (particularly when operating large, mobile machinery), for fear of losing their job, despite management claims to the contrary.

\section{High Turnover of Senior Management}

At four of the five lower-safety mine sites there was a high turnover of senior management, including mine managers. One site, for example, had lost approximately 50 percent of its senior management team in the last six to nine months, and another had several managers in the space of two and half years. Such experiences can greatly inhibit attempts to build and maintain trust between management and workers. A worker explained:

This creates inherent problems because people are unable to relate to the mine manager, they're unable to relate to the superintendent, because you can't build that trust relationship up.... With each new person [there are] new ideas, new values, new ethics, and those situations are confusing sometimes, especially for lower-level management and employees.

High turnover of management also raises doubts in the minds of workers as to the viability of the mine, as some workers interpret this as evidence that management has no long-term commitment to the mine. It also stands in stark contrast to the experience of workers, who often remain in the same job for decades. Consequently, if workers fall out with a manager, they can simply wait them out, which fosters the attitude that 'I'll still be here long after you're gone, so you've got no hold over me'. This makes it difficult to develop a sense of shared destiny and overcome mistrust.

\section{Closed Management Style}

A fifth characteristic was the wider issue of a 'closed' management style. There are a number of dimensions to this. One is the extent to which the management team is isolated from the workforce, as where they are perceived to be reclusive and isolated. This causes a distancing often accompanied by a lack of understanding of and trust in management actions. At one low-safety mine, for example, workers observed that managers 'disappear into their offices' whenever there is a change of shifts, an act that workers perceived as a cowardly way of avoiding interaction with them. At another mine, senior management is rarely seen. As one worker stated: 'I'd say 80 percent of the workforce here probably don't interact with management too much at all, except maybe when another 
manager comes into their section "How you fellows going, blah, blah, blah, see you later"'.

In contrast, at higher-safety mines, management created opportunities for informal and formal engagement, for example, taking advantage of shift changes to engage with the workforce. Workers expressed a strong preference for this style of management and reported that it was an important component of building trust.

Another aspect of a closed management style is a lack of consultation. Workers at lower-safety mines reported that management safety initiatives appear 'out of the ether', with little input from the workforce in their design or implementation. This can be particularly debilitating to the 'ownership' of safety initiatives for which worker engagement is essential. For example, at one mine there were complaints about the constant stream of new safety initiatives accompanied by little or no prior consultation with the crew, and, at another, miners were scathing about the lack of consultation in the introduction of mandatory mini risk assessments for every shift, resulting in rampant tokenism.

Particularly important, according to workers at all mines, was the extent and means by which management provided feedback, especially in the context of reporting on accidents, near misses, equipment damage and hazard identification. At some low-safety mines, responses to reports are simply posted on a noticeboard, without any feedback. In contrast, at higher-performing mines, feedback is a priority and is provided directly to the worker who is the original source of the report. This occurs even where no action is taken. Workers do not object to a no-action decision provided that they are kept informed in a timely fashion, and a reasonable explanation is provided. Not coincidentally, timely feedback served to build trust in management motives and commitment to safety.

\section{Resentment of Corporate Intervention}

As corporation-wide safety management becomes more sophisticated, this is inevitably followed by greater corporate intervention in mine site operations, including safety standards, systems, benchmarks, monitoring and accountability mechanisms. In Australia at least, this has been magnified by safety legislative requirements. These twin drivers can reduce site autonomy and, to some extent, flexibility and capacity for innovation. At some lower-performing mine sites, corporate intervention may have a second, and unintended, consequence: generating resentment and mistrust. It was striking that the three lowestperforming mines (one from each company) displayed the highest levels of mistrust towards corporate management. As one interviewee stated:

[A]t the higher levels, they've decided that they can't trust people at the mines ... 'so we're going to give them these standards or we're going to audit them against these standards and that will force them to get into line. Tell them that this is what they have to do before the next audit or there'll be consequences' and so on.

Management at each of the lowest-performing sites typically complained that the site: was an 'easy target'; was unfairly represented (as the poorest performer) 
in safety statistics and corporate audits (and other sites manipulated their results); did not have the same access to resources or quality equipment and technology as better-performing sites; was burdened with a more militant and/ or older workforce; and confronted unfavourable physical characteristics (such as fractured seams, high levels of methane, water intrusion etc.). In short, these sites maintain that the 'cards are stacked against them'. It was beyond the scope of this project to determine the validity of these claims independently. However, when these views were put to corporate managers, whilst they acknowledged that some mines do indeed confront greater physical difficulties, they rejected any consistent and causal relationship to safety performance - as evidence of this, one manager noted that their two best safety-performing mines had vastly different physical characteristics, while another asserted that a mine site that had once been one of their worst safety performers had, over several years, become one of their best performers with no discernible change in technology (over and above that of all their mines) or physical conditions.

There was an element of circularity in the phenomenon of local resentment of corporate intervention. Lower safety-performing mine sites often perceived that they were unfairly targeted. This created mistrust and resentment that undermined the success of corporate interventions and, in turn, invited further corporate scrutiny and intervention.

Two distinct types of mistrust were identifiable. First, site management doubted the competence of corporate management to carry out their stated safety intentions and this bred resentment, exemplified by the statement:

I've got no time for corporate at all. I just think they are pretty hopeless. Some of the systems, there's no communication.... Well, they just put it out, no training, no nothing, just dump it in their system.... We're always the last to find out.... Well they say every pit stands on its own. Then they want to enforce things over the top of you from corporate.

This resentment was typically coupled with a belief that corporate management had placed an unfair safety burden on the site and had failed to provide the necessary resources to discharge that burden, exemplified by the comment:

I have to say they had a point to prove and they were there to do it. They were there to give you .... an overview of your operation. The problem is that I found that some of the review, the outcomes of that audit, I didn't have ownership to say 'Well that's not my area', but it was all lumped back to me to fix it after the audit. Why? I had no resources, how the hell am I supposed to do all of this, how am I going to do it?

Others had little trust in the ability of corporate management to understand the ramifications of their safety policies. Seemingly innocuous changes can have adverse impacts at the mine level, as an interviewee explained:

What they change at the stroke of a pen can have dramatic and far-reaching consequences at the mine site. We have had to completely revise our management systems to accommodate a fickle change in one of our standards.

A second, more insidious, form of mistrust was where site management doubted the motivations of corporate management, and interpreted corporate 
intervention as an indicator of corporate mistrust in site safety competence. In some cases, this generated resentment and a barely concealed contempt:

Others I think are tolerating it [corporate intervention] because they realize that they won't get a job unless they do pay lip service to it. We have a small core of managers who think it's a load of crap and they've said so, 'This is all bullshit' and when you get to the mine level, because they think it's all bullshit, they don't do anything until the last minute and then your attempts at being professional come to nothing because you're operating without all the information.

In contrast, at many of the better safety-performing mines there is far more acceptance of the desirability, effectiveness and benefits of corporate safety interventions. Although site management readily admitted they were initially very sceptical, they changed their minds and recognized the need for greater corporate oversight and, consequently, greater site accountability. Several site managers acknowledged this had been a difficult personal journey, but that their initial opposition was unfounded. The net effect was an increase in trust of corporate safety capabilities and intentions. Management at lower-safety mines were yet to make such a transition.

\section{Conclusions}

Based on the experiences of Io mine sites across three companies and two jurisdictions, this article has identified six cluster characteristics closely connected with the development of mistrust at site level. Such mistrust has a corrosive effect on the implementation of safety initiatives at site level. Although the six cluster characteristics have been examined individually, they may interact synergistically to amplify mistrust. For example, a catalytic event, such as spilling and subsequently rehiring a workforce, can accentuate or create divisions in the workforce. Similarly, a high turnover of senior mine management positions, with the inevitable loss of corporate memory, will increase the likelihood of mixed messages being given to middle management, line managers and workers. Organizational structures can influence management style, as when a more hierarchical structure reduces opportunities for workers, middle management and senior mine management to interact, accentuating tendencies for senior management to be reclusive. Equally, combinations of opposite characteristics can interact to reduce mistrust, as when new organizational structures result in a flatter management structure that brings line management much closer to senior management.

When a sufficient number of negative characteristics are present at one mine site, it is very difficult to prevent that site from spiralling into a cycle of mistrust where every interaction or decision (including new and genuine safety initiatives) is perceived through the prism of past history and mistrust, and discounted and/or resisted accordingly. Conversely, the absence of a sufficient number of characteristics can foster the building of trust. This suggests the presence of 'tipping points' where a critical mass of characteristics is reached, 'tipping' a site down the path of mistrust. 
The behaviour of the mine sites included in this study was consistent with the tipping point hypothesis. There was a clear division between the lower- and higher-safety mines in the frequency of the cluster characteristics. The three lowest-ranked sites each possessed six of the cluster characteristics. In contrast, the five leading safety sites each had three or fewer cluster characteristics. The two remaining sites possessed four and five cluster characteristics, respectively, and were grouped with the lower-safety sites. This suggests that the presence of a relatively small number of characteristics is not sufficient to push a mine into a cycle of mistrust, but that the development of mistrust involves a majority of cluster characteristics, although the strength of each characteristic at a site will also be important.

The tipping point hypothesis suggests that once characteristics are over this point, achieving safety improvements will be extremely difficult. This may lead to extreme responses on the part of corporate management. This was evidenced at one company that closed an existing, operating mine and reopened it as a 'new' mine with a different access point. This provided the opportunity to make the old workforce redundant and to start again with a 'clean slate'. Subsequently, management selected experienced workers from the 'old' mine who were considered to be more aligned with corporate management thinking (usually, those with weaker union ties), and also selectively recruited 'suitable' applicants from outside the old mine's workforce. One mine manager summarized the rationale as follows:

\begin{abstract}
Bad culture goes with old mines. It produces an 'us and them' approach, and mistrust of management. Lots of people say the only way to change is a forced closure - to put the mine in care and maintenance for a minimum of six months and a maximum of twelve, and then cherry-pick a new workforce - there'd be high agreement on who we should not reappoint.
\end{abstract}

This is a strategy that a number of companies have contemplated. For example, one manager (who was far from alone) suggested that the only solution to dealing with a pit with a particularly acrimonious history is to 'shut and rehire'. In his view:

That should happen. You walk in and survey the whole place, identify the things going wrong - the one-and-a-half-hour cribs, that $\mathrm{X}$ goes home early on Friday and so on. So you stop all that and shut. But, you've got to get buy-in in the future from the workforce. And you've got to bypass the unions. In future, the workers must talk directly to me. Unions can be there, but then you develop milestones and guidelines, e.g. zero injuries, then you work development month by month - if they reach this milestone, this happens [a bonus] ... if not, there will be 50 percent redundancies and so on.

The danger of this approach is that it may build mistrust. A far preferable solution would be to act in ways that avoid the build-up of cluster characteristics and to ensure that the tipping point is never reached.

What wider implications do these findings have for safety beyond the mining industry? While the mining industry may be exceptional in its long and bitter history of industrial conflicts, and management-miner hostilities, in other ways 
it is not. Corporations in many industry sectors confront the problem of ensuring that their far-flung operations behave as corporate management would wish them to. Indeed, there is evidence that corporations may be mistaken in their belief that those who are encouraged or required to develop and implement safety plans, systems and other management-based strategies will necessarily improve their performance as a result (Gunningham et al., 2003; Parker and Neilson, 2006). On the contrary, it may well be (as this article suggests) that site-level management commitment is far more important than managementbased strategies, that management commitment may not exist at individual sites even if it exists at corporate management level, and that the reason for this may be the presence of mistrust.

Corporate policymakers generally, therefore, may learn much from the experience of the mining industry. While some of the cluster characteristics have particular resonance for the mining industry, the characteristics we identified can be found in other industry sectors. As such, lessons about how to avoid their formation have considerable merit, particularly for corporations committed to improving safety, but unsure how best to achieve it at site level. These lessons can be summarized as follows.

First, the role of corporate management in creating trust is very important (Hopkins, 2002 b; Whitener et al., I998). It is they who set the priorities, establish the values and provide the resources that substantially shape site management and workforce responses. Conversely, much hard work at site level can be quickly destroyed if corporate management is at odds with site management. However, it is in large part site management, not corporate management, with whom the workforce has direct contact, and it is the extent to which site management has the perceived competence, benevolence and integrity to safety values that will have most influence in shaping workforce perceptions of management commitment. It will be impossible for site management to build trust unless they not only espouse the value of a safe workplace, but also demonstrate their commitment to that value by their actions. Unless management at all levels walks the talk, then worker cynicism about their motivations will remain high. This research suggests that there are a variety of ways management can overcome this suspicion, such as by being receptive to, and responding rapidly to, safety concerns raised by the workforce.

Second, even where site (and corporate) management have a demonstrable commitment to safety, there remains a substantial impediment if the levels of middle management below them do not 'buy into' the safety message. Here, mistrust is directed more at senior management's abilities than its intentions, although the latter is sometimes also present. Pitzer, for example, found that middle management showed signs of disillusionment with corporate safety initiatives (Minerals Council of Australia [MCA], I999). The present study suggests that this sometimes morphs into resistance by site management to efforts by corporate management to impose greater accountability and responsibility upon them, particularly where this involves substantive reporting, auditing and management systems (these research findings have significant implications for safety cultures and corporate safety management systems and warrant 
elaboration - these issues are dealt with in detail by the authors in a separate, forthcoming article; Gunningham and Sinclair, forthcoming [b]). A related issue is the devolution of safety decision-making and the extent to which workers are empowered to deal with safety issues. Workers were far more likely to accept and implement safety initiatives if they had a high degree of ownership.

Third, overtly hierarchical relationships serve to constrain trust, as the organizational trust literature demonstrates. Those at the bottom often have a fear of exploitation and suspicion that they are being treated unfairly, while those at the top suspect that the individuals for whom they are responsible are shirking responsibility or engaging in acts that might endanger the organization (Kramer, I996: 2 I6). In the present research, this occurred with line managers, many of whom reported a lack of support from senior management, with consequences for their trust in those above them. Workers also reported that flat structures and a lack of demarcation between jobs achieved real benefits, and many saw value in management not interfering in day-to-day issues.

Fourth, communication is an important factor in overcoming mistrust. A distinctive feature of high-safety mines was the high level of communication between workers and management. No single, successful formula for communication could be identified (communication could be as informal as after-work barbeques or as formal as weekly safety committee meetings), and much depends on personal management style. This is consistent with the finding of Cox et al. (2006: I I26) that 'managers who are willing to share information signal to their employees that they can be trusted'.

Fifth, and closely related, is management's willingness to listen and respond to workers' safety concerns. Workers appreciated managers who acted promptly when they expressed safety concerns, even when this was only to explain why they did not propose to take any further action. What Reason (I997) terms a 'reporting culture' can only be established when those who report such incidents trust that they will not be punished, or in any way adversely treated, for doing so (a 'blame-free' culture). This is a good indicator because workers take a risk in reporting incidents in which they may be at fault, and will only do so where they are confident that they will not be punished as a consequence. This is part of a broader issue: the perception of workers that they will be treated fairly or justly that, as Tyler et al. (I997) have demonstrated, can serve to reinforce trust. A just culture has been described as 'comprising an atmosphere of trust in which people are encouraged, even rewarded, for providing essential information, but in which they are also clear about where the line must be drawn between acceptable and unacceptable behaviour' (Cox et al., 2006: I 24). Accordingly, it is only in these circumstances that workers are likely to act in the collective good. This points to a sixth characteristic of 'high-trust' organizations: an expectation that managers will act with 'consistency, integrity and concern', even during periods of conflict or crisis.

All of the above serve to illustrate that trust, and mistrust, are multifaceted. At the very least, the aspects of trust identified here are mutually reinforcing, and some of them are so fundamental that it is difficult to conceive of trust developing in their absence. While these are necessary conditions for the 
creation of trust, they are insufficient in themselves. Without effective worker engagement, trust between workers and managers clearly cannot be achieved. Accordingly, the other criteria described earlier are all important in the composite picture, albeit that trust might develop in the absence of a small number of them.

\section{Acknowledgement}

The authors would like to acknowledge the valuable contribution of their colleague Liz Bluff in reviewing earlier drafts of the article.

\section{Funding}

The research on which this article draws was supported by an Australian Research Council Linkage Grant.

\section{Notes}

I A five-year period was chosen because this was the extent to which companies could provide consistent data, and was deemed to be sufficient to overcome annual aberrations.

2 Subsequent to the research, the mine sites of one of the companies underwent comprehensive international safety audits conducted by a specialist team of auditors from their international headquarters, the results of which were entirely consistent with our own safety rankings - this provided external support as to the credibility of our ranking methodology.

3 This process was in accordance with the ethics clearance provided by The Australian National University to the authors for conducting the research.

\section{References}

ACiL (2005) Final Report on the Queensland Mines Inspectorate Review. Brisbane: ACiL Tasman, New Horizon Consulting Pty Ltd, Shaw Idea Pty Ltd.

Barling J and Hutchinson I (2000) Commitment vs control-based safety practices, safety reputation and perceived safety climate. Canadian Fournal of Administrative Sciences I7(I): $76-84$.

Bennett L (1994) Making Labour Law in Australia. Sydney: Law Book Company.

Berman D (1978) Death on the Fob. New York: Monthly Review Press.

Bijlsma KM and Koopman P (2003) Introduction: Trust within organizations. Personnel Review 32(5): 543-555.

Bullimore K (I999) I949 coal strike: Labor's 'boots and all' sell out. Green Left Weekly, January.

Carson WG (1981) The Other Price of Britain's Oil: Safety and Control in the North Sea. Oxford: Martin Robertson.

Carson WG and Hennenberg C (I988) The political economy of legislative change: Making sense of Victoria's new occupational health and safety legislation. Law in Context 6(2): I-I 9 .

Chandler R (2009) Magistrates Court of Tasmania, Coronial Division, in the matter of the Coroners ACT I995 and in the matter of an inquest touching the death of Larry Paul Knight, findings, recommendations and comments of Coroner Rod Chandler following an inquest held in Launceston on 22 July to 25 September and I I November 2008. 
Available at: http://www.magistratescourt.tas.gov.au/_data/assets/pdf_file/oo I6/I I 7430/ KNIGHT,_Larry_Paul_-_2009_TASCD_25.pdf (accessed 20 December 2010).

Charmaz K (2006) Constructing Grounded Theory: A Practical Guide Through Qualitative Analysis. London: SAGE Publications.

Conchie SM, Donald IJ and Taylor PJ (2006) Trust: Missing piece(s) in the safety puzzle. Risk Analysis 26(5): 1097-I I04.

Cox S, Jones B and Collinson D (2006) Trust relations in high reliability organizations. Risk Analysis 26(5): I I $23-\mathrm{II} 38$.

Cox S, Jones B and Rycraft H (2004) Behavioural approaches to safety management within nuclear reaction plants. Safety Science 42: 825-839.

Creighton WB and Gunningham N (eds) (1985) The Industrial Relations of Occupational Health and Safety. Sydney: Croom Helm.

Cummings LL and Bromley P (1996) The organizational trust inventory. Development and validation. In: Kramer RM and Tyler TR (eds) Trust in Organisations. London, Thousand Oaks, CA, and New Delhi: SAGE, 302-330.

Dirks KT and Ferrin DL (2002) Trust in leadership: Meta-analytic findings and implications for research and practice. Fournal of Applied Psychology 87: 61 I-628.

Gunningham N and Sinclair D (forthcoming a) Building Trust - OHS Management in the Mining Industry, National Research Centre for Occupational Health and Safety Regulation, Working Paper. Available at: http://ohs.anu.edu.au/.

Gunningham N and Sinclair D (forthcoming b) Culture Eats Systems for Breakfast: Explaining Variation in Safety Performance Within an Australian Coal Mining Company.

Gunningham N, Kagan R and Thornton D (2003) Shades of Green: Business, Regulation and Environment. California: Stanford University Press.

Hargraves, AJ (ed.) (I993) History of Coal Mining in Australia. Melbourne: The Australasian Institute of Mining \& Metallurgy.

Hopkins A (2002a) Lessons from Longford: The Trial. Australia: CCH Australia.

Hopkins A (2002b) Safety culture, mindfulness and safe behaviour. Working paper 7 , National Research Centre for Occupational Health and Safety Regulation. Available at: http://ohs.anu.edu.au/ (accessed 8 March 2007).

Kramer RM (1996) Divergent realities and convergent disappointments in the hierarchic relation: Trust and the intuitive auditor at work. In: Kramer RM and Tyler TR (eds) Trust in Organisations. London, Thousand Oaks, CA, and New Delhi: SAGE, 2 I 6-245.

McColl CD (1982) A review of labour relations in the Australian black coal industry. Working paper no. 42, Centre for Applied Economic Research, The University of NSW.

Melick AG (2006) Beaconsfield investigation report prepared for the Coroner at the request of the Tasmanian Government concerning the incident resulting in the death of Larry Knight and the entrapment of Todd Russell and Brant Webb which occurred at the Beaconsfield Gold Mine (BGM), on 25 April 2006. Available at: http://www.magistratescourt.tas.gov.au/_data/assets/pdf_file/0005/I20884/alx.016.002.0002_001.pdf (accessed 22 December 2010).

Minerals Council of Australia (MCA) (r 999) Minerals Council of Australia, Australian minerals industry safety culture survey report. Available at: http://www.safemap.com/ common/pdfs/MCA\% 20CULTURE\% 20SURVEY\% 20SUMMARY\% 20REPORT.pdf (accessed 6 March 2007).

Morgan RM and Hunt SD (1994) The commitment-trust theory of relationship marketing. Journal of Marketing 58: 20-38.

New South Wales Minerals Council (NSWMC) (2005) New South Wales Minerals Council, Submission to the 2005 NSW Mines Safety Review, Sydney. 
Nichols T and Armstrong P (1973) Safety or Profit: Industrial Accidents and the Conventional Wisdom. Bristol: Falling Water Press.

Parker C and Nielson V (2006) Do businesses take compliance systems seriously? An empirical study of implementation of trade practices compliance systems in Australia. Melbourne University Law Review 30(2): 44I-494.

Quinlan M (2007) Beaconsfield investigation report, annexure BD. Available at: http:// www.magistratescourt.tas.gov.au/_data/assets/pdf_file/0004/I 20946/alx.0 I6.002.00 I I.pdf (accessed 20 December 2010).

Reason J (1997) Managing the Risks of Organizational Accidents. Aldershot: Ashgate.

Risk Analysis (2006) Special issue on trust. Risk Analysis 26(5): 1097-I407.

Ritter M (2004) Ministerial inquiry: Occupational health and safety systems and practices of BHP Billiton Iron Ore and Boodarie Iron sites in Western Australia and related matters. Available at: http://www.dmp.wa.gov.au/documents/Reports/MSH_RitterReportVolıof2.pdf (accessed I2 July 20II).

Robens R (1972) Safety and Health at Work: Report of the Committee, 1970-72. London: HMSO.

Shaw AGL and Bruns GR (I947) The Australian Coal Mining Industry. Melbourne: Melbourne University Press.

Tyler TR (2003) Procedural justice, legitimacy, and the effective rule of law. Crime and fustice 30: $283-357$.

Tyler TR, Boeckmann R, Smith HJ, et al. (1997) Social fustice in a Diverse Society. Colorado: Westview Press.

Whitener EM, Brodt SE, Korsgaard MA, et al. (I998) Managers as initiators of trust: An exchange relationship framework for understanding managerial trustworthy behavior. The Academy of Management Review 23(3): 513-530.

Wran N and McClelland J (2005) NSW mines safety review: Report to the Hon Kerry Hickey MP Minister for Resources. Available at: http://www.dpi.nsw.gov.au/minerals/ safety/mine-safety-initiatives/wran-mine-safety-review/ (accessed I 5 January 2007).

Zeffane R and Connell J (2003) Trust and HRM in the new millennium. International fournal of Human Resource Management I4(2): I-9. 